Semi-Infinite Programming 


\section{Nonconvex Optimization and Its Applications}

Volume 57

Managing Editor:

Panos Pardalos

University of Florida, U.S.A.

Advisory Board:

J.R. Birge

Northwestern University, U.S.A.

Ding-Zhu Du

University of Minnesota, U.S.A.

C. A. Floudas

Princeton University, U.S.A.

J. Mockus

Lithuanian Academy of Sciences, Lithuania

H. D. Sherali

Virginia Polytechnic Institute and State University, U.S.A.

G. Stavroulakis

University of Ioannina, Greece

The titles published in this series are listed at the end of this volume. 


\section{Semi-Infinite Programming}

Recent Advances

Edited by

Miguel Á. Goberna and Marco A. López

Universidad de Alicante, Spain

Springer-Science+Business Media, B.V. 
A C.I.P. Catalogue record for this book is available from the Library of Congress.

ISBN 978-1-4419-5204-2 ISBN 978-1-4757-3403-4 (eBook)

DOI 10.1007/978-1-4757-3403-4

Printed on acid-free paper

All Rights Reserved

(C) 2001 Springer Science+Business Media Dordrecht

Originally published by Kluwer Academic Publishers in 2001.

Softcover reprint of the hardcover 1st edition 2001

No part of the material protected by this copyright notice may be reproduced or utilized in any form or by any means, electronic or mechanical, including photocopying, recording or by any information storage and retrieval system, without written permission from the copyright owner. 
To Rainer Hettich and Werner Oettli, in memorian 


\section{Contents}

Preface $\quad$ xi

Contributing Authors $\quad$ XV

\section{Part I HISTORY}

1 ON THE 1962-1972 DECADE OF SEMI-INFINITE PRO- 3 GRAMMING: A SUBJECTIVE VIEW

Ken O. Kortanek

1 Introduction: Origins of a theory

2 Generalized linear programming and the moment problem 7

3 Using the 1924 Haar result on inhomogeneous linear inequalities

$4 \quad$ Introducing an infinity into semi-infinite programming

5 A classification of duality states based on asymptotic consistency

6 Asymptotic Lagrange regularity

7 Applications to economics, game theory, and air pollution abatement

8 Algorithmic developments: "Matching of the derivatives" 31

$9 \quad$ Epilog

References

\section{Part II THEORY}

2 ABOUT DISJUNCTIVE OPTIMIZATION

Ivan I. Eremin

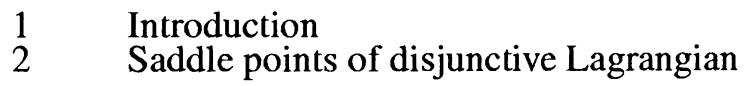

3 Duality framework

$4 \quad$ An exact penalty function method 
3 ON REGULARITY AND OPTIMALITY IN NONLINEAR SEMI-INFINITE PROGRAMMING

Abdelhak Hassouni and Werner Oettli

$\begin{array}{lll}1 & \text { Introduction } & 59 \\ 2 & \text { The linear case } & 60 \\ 3 & \text { The convex case } & 61 \\ 4 & \text { Convex approximants } & 66 \\ 5 & \text { The exchange method for semi-infinite convex minimization } & 68 \\ 6 & \text { Normal cones and complementary sets } & 71 \\ \text { References } & 74\end{array}$

4 ASYMPTOTIC CONSTRAINT QUALIFICATIONS AND ERROR BOUNDS FOR SEMI-INFINITE SYSTEMS OF CONVEX INEQUALITIES

$W u$ Li and Ivan Singer

$\begin{array}{lll}1 & \text { Introduction } & 75 \\ 2 & \text { Preliminaries } & 77 \\ 3 & \text { Asymptotic constraint qualifications. The sup-function method } & 80 \\ 4 & \text { Error bounds for semi-infinite systems of convex inequalities } & 90 \\ 5 & \text { Error bounds for semi-infinite systems of linear inequalities } & 95 \\ \text { References } & 99\end{array}$

5 STABILITY OF THE FEASIBLE SET MAPPING IN CON- 101 VEX SEMI-INFINITE PROGRAMMING

Marco A. López and Virginia N. Vera de Serio

1 Introduction 101

2 Preliminaries 103

3 A distance between convex functions 104

4 Stability properties of the feasible set mapping 105

References

6 ON CONVEX LOWER LEVEL PROBLEMS IN GENERAL- 121 IZED SEMI-INFINITE OPTIMIZATION

Jan-J. Rückmann and Oliver Stein

1 Introduction 121

.2 The local topology of $M \quad 123$

3 A local first order description of $M \quad 126$

4 First order optimality conditions 130

$5 \quad$ Final remarks 132

References 
Alexander Shapiro

$\begin{array}{lll}1 & \text { Introduction } & 135 \\ 2 & \text { Conic linear problems } & 136 \\ 3 & \text { Problem of moments } & 145 \\ 4 & \text { Semi-infinite programming } & 152 \\ 5 & \text { Continuous linear programming } & 155 \\ \text { References } & 164\end{array}$

\section{Part III NUMERICAL METHODS}

8 TWO LOGARITHMIC BARRIER METHODS FOR CON- 169 VEX SEMI-INFINITE PROBLEMS

Lars Abbe

1 Introduction 169

2 A bundle method using $\varepsilon$-subgradients $\quad 170$

3 Description of the barrier method 172

$4 \quad$ Properties of the method 175

$5 \quad$ Numerical aspects 181

6 Numerical example 182

7 A regularized log-barrier method 185

$8 \quad$ Numerical results of the regularized method 191

9 Conclusions 193

References 194

9 FIRST-ORDER ALGORITHMS FOR OPTIMIZATION 197

PROBLEMS WITH A MAXIMUM EIGENVALUE/

SINGULAR VALUE COST AND OR CONSTRAINTS

Elijah Polak

1 Introduction 197

2 Semi-Infinite Min-Max Problems 199

3 Rate of Convergence of Algorithm 2.2 206

4 Minimization of the Maximum Eigenvalue of a Symmetric Matrix 207

5 Problems with Semi-Infinite Constraints 211

6 Problems with Maximum Eigenvalue Constraints 216

7 Rate of Convergence of Algorithm 5.1 216

8 A Numerical Example 217

9 Conclusion 219

References $\quad 219$ 
ANALYTIC CENTER BASED CUTTING PLANE 221 METHOD FOR LINEAR SEMI-INFINITE PROGRAMMING

Soon-Yi Wu, Shu-Cherng Fang and Chih-Jen Lin

1 Introduction

2 Analytic Center Based Cuts

3 Analytic Center Cutting Plane Method for LSIP

4 Convergence and Complexity

References

\section{Part IV MODELING AND APPLICATIONS}

11 ON SOME APPLICATIONS OF LSIP TO PROBABILITY AND STATISTICS

Marco Dall'Aglio

$\begin{array}{lll}1 & \text { Introduction } & 237 \\ 2 & \text { De Finetti coherence } & 238 \\ 3 & \text { Constrained maximum likelihood estimation of a covariance } & 246 \\ 4 & \text { matrix } & 247 \\ \text { LSIP in actuarial risk theory } & 254\end{array}$

12 SEPARATION BY HYPERPLANES: A LINEAR SEMI- 255 INFINITE PROGRAMMING APPROACH

Miguel A. Goberna, Marco A. López and Soon-Yi Wu

1 Introduction

3 Strong separation of compact sets in separable normed spaces 262

4 Strong separation of finite sets in the Hadamard space 265

References

13 A SEMI-INFINTE OPTIMIZATION APPROACH TO OPTIMAL SPLINE TRAJECTORY PLANNING OF MECHANICAL MANIPULATORS

Corrado Guarino Lo Bianco and Aurelio Piazzi

1 Introduction

2 Cubic spline trajectory planning under torque and velocity constraints

3 A feasibility result

4 Problem solution using an hybrid algorithm

5 Penalty computation via interval analysis

6 An Example

7 Conclusions 
$\begin{array}{ll}\text { References } & 295\end{array}$

14 ON STABILITY OF GUARANTEED ESTIMATION PROBLEMS: ERROR BOUNDS FOR INFORMATION DOMAINS AND EXPERIMENTAL DESIGN

Mikhail I. Gusev and Sergei A. Romanov

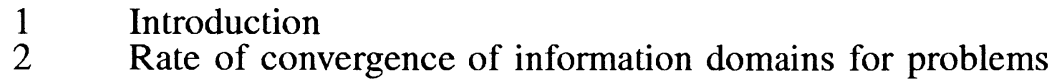
with normally resolvable operator

3 Optimal placement of sensors for nonstationary system: Duality theorems

4 Optimal sensor placement: the stationary case

OPTIMIZATION UNDER UNCERTAINTY AND LINEAR SEMI-INFINITE PROGRAMMING: A SURVEY

Teresa León and Enriqueta Vercher

$\begin{array}{lll}1 & \text { Introduction } & 327 \\ 2 & \text { Fuzzy sets } & 329 \\ 3 & \text { Convex programming with set-inclusive constraints } & 331 \\ 4 & \text { Fuzzy mathematical programming } & 337 \\ 5 & \text { Linear semi-infinite programming } & 341 \\ 6 & \text { Numerical Results } & 345 \\ \text { References } & 346\end{array}$

16 SEMI-INFINITE ASSIGNMENT AND TRANSPORTATION

\section{GAMES}

Joaquín Sánchez-Soriano, Natividad Llorca, Stef Tijs and Judith Timmer

1 Introduction $\quad 349$

2 Finite transportation and assignment games 350

$3 \quad$ Semi-infinite assignment games 353

$4 \quad$ Semi-infinite transportation problems and related games 356

5 Final remark 362

References $\quad 362$

17 THE OWEN SET AND THE CORE OF SEMI-INFINITE 365

\section{LINEAR PRODUCTION SITUATIONS}

Stef Tijs, Judith Timmer, Natividad Llorca and Joaquín Sánchez-Soriano

1 Introduction 365

2 Finite linear production situations 366

3 Semi-infinite LP situations 370

4 Finite LTP situations $\quad 374$

$5 \quad$ Semi-infinite LTP situations 379 
xii SEMI-INFINITE PROGRAMMING. RECENT ADVANCES

6 Conclusions

385

References 


\section{Preface}

Semi-infinite programming (SIP) deals with optimization problems in which either the number of decision variables or the number of constraints is finite. Hence SIP occupies an intermediate position between ordinary mathematical programming and fully general optimization.

Although SIP theory is quite old -recall the classical work of Haar on linear semi-infinite systems and the John's optimality conditions for SIP problems, published in 1924 and 1948, respectively-, the term appeared by the first time in a paper of Charnes, Cooper, and Kortanek (1962) devoted to duality in linear SIP. The last author also contributed significantly to the development of the first applications of SIP in economics, game theory, and air pollution control. Gustafson and Kortanek proposed -during the firsts 1970s- the first numerical methods for the effective treatment of the SIP models arising in these applications. Two decades after its inception, the publication around 1980 of five books converted SIP in a mature and independent optimization chapter. These books were two volumes of Lecture Notes on Mathematics devoted to SIP -edited by Hettich (in 1979), and by Fiacco and Kortanek (in 1983), respectively-, and three monographs on linear SIP (by Tichatschke, 1981), on numerical methods in SIP and their applications to approximation problems (by Hettich and Zencke, 1982), and another one on stability in SIP (by Brosowski, 1982).

Since then many papers are published every year on the theory, methods and applications of SIP and its extensions. Consequently, SIP conferences are organized regularly in order to communicate the recent advances in the field, establishing new challenges for researchers. SIP'96 took place in Cottbus, Germany, giving rise to the book Semi-Infinite Programming (R. Reemtsen and J.-J. Rückmann, editors, Kluwer, 1998). The present volume is based upon the last conference of this series, SIP'99, held in Alicante, Spain, and its purpose is to update the state-of-the art in a suggestive way, bringing the powerful SIP tools close enough to the potential users in different scientific and technological fields. 
The volume is divided into four parts, devoted to the history, theory, methods and applications (in the large sense of the term) of SIP and related topics, respectively. Part I contains a unique paper reviewing the first decade of SIP (1962-1972). His author, K.O. Kortanek -one of the main protagonists of this period-dedicates his paper to one of the main contributors to the development of SIP, Rainer Hettich, who sadly passed away in June 2000.

Part II contains six theoretical papers. Three of them deal with convex SIP from different perspectives: constraint qualifications and error bounds (by W. Li and I. Singer), stability of the feasible set (M.A. López and V. Vera de Serio), and regularity and optimality conditions (by A. Hassouni and W. Oettly, who also died during the preparation of this book). The remaining papers are focussed on different extensions of SIP: conic linear programming (by A. Shapiro), generalized SIP (by J.-J. Rückmann and O. Stein), and disjunctive programming (by I. Eremin).

Part III contains three works exclusively devoted to the numerical treatment of different families of SIP problems and extensions. They propose an analytic center cutting plane method for linear SIP (S.-Y- Wu, S.-Ch. Fang and Ch. Lin), two logarithmic barrier methods for convex SIP (L. Abbe), and first order methods for a class of problems which contains continuously differentiable SIP problems as a particular case (E. Polak), respectively.

Finally, Part IV includes seven contributions on the connections between SIP and different fields. Those presenting numerical experiments are related to probability and statistics (by M. Dall'Aglio), optimization under uncertainty (by T. León and E. Vercher) and the design of mechanical manipulators (by C. Guarino Lo Bianco and A. Piazzi), respectively. Two of the remaining papers deal with semi-infinite games (both of them authored by N. Llorca, J. SánchezSoriano, S. Tijs, and J. Timmer). Moreover, this part contains a paper on the separation of sets in normed spaces (by M.A. Goberna, M.A. López, and S.$\mathrm{Y}-\mathrm{Wu}$ ), and another one related to error bounds for information domains and experimental design (by M.I. Gusev and S.A. Romanov).

We would like to express our gratitude to all the contributors for their highquality papers, and to the referees for their valuable reports. We are very much indebted to Dr. L. Cánovas for his help in the careful preparation of the camera-ready manuscript. Last but not least, our thanks to J.R. Martindale and the staff of Kluwer Academic Publishers for having accepted the edition of this book, and for their comprehension of the six months delay in the presentation of the manuscript. This delay is the consequence of the search of a compromise between two conflicting objectives: minimizing the publication time and maximizing the quality of the book, through succesive corrections.

Alicante, May 2001.

Miguel A. Goberna and Marco A. López 


\section{Contributing Authors}

Lars Abbe. Department of Mathematics, University of Trier, Trier (Germany).

Marco Dall'Aglio. Dipartimento di Scienze, Università "G. d'Annunzio", Pescara (Italy).

Ivan Eremin. Department of Mathematical Programming, Institute of Mathematics and Mechanics, Ekaterinburg (Russia).

Shu-Cherng Fang. Operations Research and Industrial Engineering, North Carolina State University, Raleigh (USA)

Miguel Ángel Goberna. Departament of Statistics and Operations Research, University of Alicante, Alicante (Spain).

Corrado Guarino Lo Bianco. Dipartimento di Ingegneria dell'Informazione, Università di Parma, Parma (Italy).

Mikhail I. Gusev. Institute of Mathematics and Mechanics, Ural Branch of the Russian Academy of Sciences, Ekateringburg (Russia).

Abdelhak Hassouni. Département de Mathématiques et Informatique, Université Mohammed V, Rabat (Morocco).

Ken O. Kortanek. Department of Management Sciences, University of Iowa, Iowa (USA). 
Teresa León. Departament d'Estadística i Investigació Operativa, Universitat de València, Valencia (Spain).

Wu Li. Department of Mathematics and Statistics, Old Dominion University, Norfolk (USA).

Chih-Jen Lin. Department of Computer Science and Information Engineering, National Taiwan University, Taipei (Taiwan).

Natividad Llorca. Department of Statistics and Applied Mathematics, Miguel Hernández University, Elche (Spain).

Marco A. López. Department of Statistics and Operations Research, University of Alicante, Alicante (Spain).

Werner Oettli. Fakultät für Mathematik und Informatik, Universität Mannheim, Mannheim (Germany).

Elijah Polak. Department of Electrical Engineering and Computer Sciences, University of California, Berkeley (USA).

Aurelio Piazzi. Dipartimento di Ingegneria dell'Informazione,Università di Parma, Parma (Italy).

Sergei A. Romanov. Institute of Mathematics and Mechanics, Ural Branch of the Russian Academy of Sciences, Ekateringburg (Russia).

Jan-J. Rückmann. Institut für Mathematik, Technische Universität Ilmenau, Ilmenau (Germany).

Joaquín Sánchez-Soriano. Department of Statistics and Applied Mathematics, Miguel Hernández University, Elche (Spain).

Alexander Shapiro. School of Industrial and Systems Engineering, Georgia Institute of Technology, Atlanta (USA).

Ivan Singer. Institute of Mathematics, Bucharest (Romania). 
Oliver Stein. Lehrstuhl C für Mathematik, RWTH Aachen, Aachen (Germany).

Stef Tijs. Center and Department of Econometrics, Tilburg University, Tilburg (The Netherland).

Judith Timmer. Center and Department of Econometrics, Tilburg University, Tilburg (The Netherland).

Virginia N. Vera de Serio. Faculty of Economic Sciences, Universidad Nacional de Cuyo, Mendoza (Argentina).

Enriqueta Vercher. Departament d'Estadística i Investigació Operativa, Universitat de València, Valencia (Spain).

Soon-Yi Wu. Department of Mathematics, National Cheng Kung University, Tainan (Taiwan). 